\title{
Implications of Current Ecological Thinking for Biodiversity Conservation: a Review of the Salient Issues
}

\author{
$\underline{\text { Tabatha J. Wallington }}{ }^{1}, \underline{\text { Richard J. Hobbs, and Susan A. Moore }}$
}

\begin{abstract}
Given escalating concern worldwide about the loss of biodiversity, and given biodiversity's centrality to quality of life, it is imperative that current ecological knowledge fully informs societal decision making. Over the past two decades, ecological science has undergone many significant shifts in emphasis and perspective, which have important implications for how we manage ecosystems and species. In particular, a shift has occurred from the equilibrium paradigm to one that recognizes the dynamic, nonequilibrium nature of ecosystems. Revised thinking about the spatial and temporal dynamics of ecological systems has important implications for management. Thus, it is of growing concern to ecologists and others that these recent developments have not been translated into information useful to managers and policy makers. Many conservation policies and plans are still based on equilibrium assumptions. A fundamental difficulty with integrating current ecological thinking into biodiversity policy and management planning is that field observations have yet to provide compelling evidence for many of the relationships suggested by non-equilibrium ecology. Yet despite this scientific uncertainty, management and policy decisions must still be made. This paper was motivated by the need for considered scientific debate on the significance of current ideas in theoretical ecology for biodiversity conservation. This paper aims to provide a platform for such discussion by presenting a critical synthesis of recent ecological literature that (1) identifies core issues in ecological theory, and (2) explores the implications of current ecological thinking for biodiversity conservation.
\end{abstract}

Key Words: biodiversity conservation; disturbance; ecosystem management; non-equilibrium ecology; spatial dynamics; temporal dynamics; theoretical ecology

\section{INTRODUCTION}

The science of ecology has been the subject of considerable criticism recently, much of which centers on the gulf between ecological theory and its practical application. In particular, ecology has been condemned for failing to provide information that is relevant to management and policy (cf. Baskerville 1997 and associated commentary). This situation has been further complicated in the past 30 or so years, as many concepts that were considered central to ecology in previous decades have since been revised. These shifts in emphasis and perspective have important implications for how we manage ecosystems and species (Botkin 1990, Pimm 1991, Pickett et al. 1992, Knight and Bates 1995, Hobbs and Morton 1999).
The fundamental shift in ecological thinking centers on the change in perception of ecosystems from static entities in equilibrium to complex systems that are dynamic and unpredictable across time and space (Scoones 1999). Yet, despite widespread agreement among ecologists that "classical equilibrium theories are woefully inadequate" (Levin 1999a, 1999b), current policies and plans do not reflect emerging scientific perspectives. As Jane Lubchenco reported, "[a]ll too many of our current environmental policies and much of the street lore about the environment are based on the science of the 1950s, 1960s, and 1970s, not the science of the 1990s" (Lubchenco 1998: 495). As such, most current approaches to biodiversity conservation, which rely primarily upon reserves to protect 
diversity in situ, are based on the classic view of ecosystems in static equilibrium (Lister and Kay 1999). Ecological concepts ranging from succession, island biogeography, and carrying capacity, to the systems ideas of ecosystem theory, are all dominated by equilibrium assumptions (Scoones 1999). Moreover, most senior conservation managers and policy makers trained at a time when equilibrium thinking was prevalent.

A difficulty with integrating current ecological thinking into policy is that field observations have yet to provide sufficiently compelling evidence for many of the relationships suggested by current theories in ecology. This is a notable feature of any science in transition (Holling 1998), where uncertainty and debate characterize inquiry at the "frontiers of science" (Pickett et al. 1994). Indeed, the relative youth of ecology as a science has meant that the theoretical building blocks of ecology have always been vigorously debated in the ecological literature. Yet, although this kind of debate is the mark of a healthy scientific community, it often means that ecological research is less useful to policy makers and managers than it might otherwise be. It is difficult for managers and policy makers to know which theories are important, and how much uncertainty is associated with current ecological knowledge (Hobbs 1998).

General ecological theory can, should, and does inform management of particular situations, in particular places (Lawton 1996). The influence that ongoing advances in ecological science have on this process depends critically on a commitment by ecologists to engage with questions concerning the conservation role of ecology. The translation of ecological theories into information that is relevant to biodiversity conservation is a challenge that must be taken up by the scientific community (Brosnan 1995).

Ecologists have, in the past, been reluctant to engage in applied research (Hobbs 1998), in part because the association with often emotionally charged conservation issues can mean that the science is perceived as advocacy (Levin 1999b). However, the role of scientists in the pursuit of research into socially relevant questions should not be confused with advocacy, in a narrowly defined political sense. Conservation science is, by definition, a normative science (cf. Barry and Oelschlaeger 1996). Conservation scientists have a responsibility to ensure that research facilitates the long-term persistence of its object of study: the diversity of life on Earth.

It is the intention of this paper to provide a platform for debate on core issues in theoretical ecology, and their implications for biodiversity conservation. The discussion that follows presents a critical synthesis of recent ecological literature in order to (1) clarify the status of current ideas in ecological theory, and (2) explore the implications of current ecological thinking for biodiversity conservation. As such, the first part of the paper outlines the core concepts in non-equilibrium ecology, before going on to discuss whether the recent shift in emphasis from equilibrium to non-equilibrium ideas represents a paradigm shift in ecology. The next part of the paper explores the implications of nonequilibrium ecology for biodiversity conservation. Concluding remarks close the paper.

\section{CORE CONCEPTS IN NON-EQUILIBRIUM ECOLOGY}

We begin this discussion from the assumption that ecological science is in transition (Holling 1998). Central to this transition is a shift in emphasis from equilibrium to non-equilibrium dynamics in theoretical ecology. It is important to note at the outset, however, that although current developments in non-equilibrium ecology emphasize the complexity and non-linearity of ecosystem dynamics, these ideas are not new. The dynamic and non-linear nature of ecosystem development was recognized by Gleason $(1926,1927)$ in the early 1900 s, for example. Thus, it may be that these are old ideas that were originally presented before their time (Halvorson 2004). More recent work by Holling (1973) and May (1977) refocused attention on the non-equilibrial nature of ecosystems, and these ideas have gained increasing prominence in the ecological literature since that time. The following discussion outlines the revisions to core concepts in ecology facilitated by this recent shift in emphasis, which centers around the spatial and temporal dynamics of ecological systems.

\section{Temporal Dynamics}

Disturbance, historical contingency, and multiple stable states

The essence of the classic paradigm in ecology is 
the idea that, in the absence of human interference, ecological systems may be characterized in terms of an ideal, stable state of equilibrium (Botkin 1990). The core ideas may be summarized as follows:

The classical paradigm in ecology ... emphasized the stable point equilibrium of ecological systems.... The major engine of succession was considered to be the attainment of the climax state. The processes involved necessarily led to that state, and deviations were of little fundamental interest. (Pickett et al. 1992: 67.)

Thus, a feature of the classic paradigm in ecology is the assumption that ecosystems follow a linear path of development toward a particular, biologically diverse, and stable "climax" state (Fiedler et al. 1997). Disturbance (fire, insects, disease) is considered to be a rare, external event, rather than an intrinsic property of the community and is, therefore, something managers should eliminate (Hobbs and Huenneke 1992). Because it is assumed that nature is governed by mechanistic natural laws that people can know (Langston 1998), the endpoint of ecosystem development is both inherently predictable, and the assumed goal of management.

Research since the early 1970 s has shown this view to be incomplete, however. These developments deny the foundational status of stable-point equilibrium systems and climax states for ecological understanding (Egerton 1973). Rather, emphasis is directed to the dynamic, complex, nonequilibrial nature of ecological systems (Pickett et al. 1992). According to this view, successional processes are much less deterministic than previously thought (Pahl-Wostl 1995). The view is of a much more open system that exists in a constant state of flux, usually without long-term stability (Hobbs and Morton 1999). Divergence from a given state-whether brought about by natural catastrophe, such as fire or flood, or by human-induced disturbance-is considered to be a common event (Lister and Kay 1999). Disturbance is also recognized to be an inherent feature of the internal dynamics of ecosystems, and may set the timing of successional cycles (Holling et al. 1995). Frequent disturbance makes ecosystems subject to sudden, unpredictable change, which may cause systems to suddenly "flip" into entirely new states (Holling et al. 1995, Peterson et al. 1998). As such, uncertainty is normal, and predictable end-points to successional processes are not always apparent. Equilibria are temporary artefacts of observation, not intrinsic system properties.

The centrality of disturbance, and the contingency of the consequent course of succession, brings history to the fore (Fiedler et al. 1997, Hobbs and Morton 1999). System history emphasizes the contingency of current conditions so that the unique nature of a specific site is based on a particular history of events, including the composition and pattern of those events (Parker and Pickett 1998). Long-term ecological research has revealed that the legacies of historical land-use activities continue to influence the long-term composition, structure, and function of most ecosystems and landscapes for decades and centuries after the activity has ceased (Bellemare et al. 2002, Foster et al. 2003). As a consequence, present ecosystem conditions must be understood in the context of a trajectory of change that encompasses past land use, climate, and natural disturbance, in addition to endogenous successional processes.

Historical contingency, therefore, reflects the cumulative pattern of the impact of a diversity of processes at various scales. All processes act in the context of other processes, and their temporal sequence may be critical. As a consequence, the endpoint of many successional processes is not a predictably uniform outcome; rather, several states are possible depending on the contingent circumstances. These multiple states may be stable for long periods of time, depending on the particular circumstances of the disturbance and the nature of the biophysical conditions that precede and follow it (Hobbs and Morton 1999).

In the context of sustainability, the goal of conserving biodiversity for the benefit of future generations determines the temporal horizon of biodiversity policy (Norton and Ulanowicz 1992). Thus, long-term trends in system variability are critical (Sprugel 1991). Structural processes organize behavior as a nested hierarchy of cycles of slow production and growth alternating with fast disturbance and renewal (Holling et al. 1995). Moreover, it is increasingly clear that episodic rapid change is normal (Lister 1998).

Most pressing environmental problems are caused by slow changes (in atmospheric composition, land use, etc.) that occur gradually and over time horizons longer than the human attention span. 
Gradual changes (which humans tend to ignore) are likely to result in more rapid changes that arrive as a surprise and may have drastic consequences (Holling 1986, Hobbs 1992). Rare events, management disturbances, and resource exploitation can all unpredictably shape system structure at critical times or at locations of increased vulnerability, and may even cause the system to "flip" into a new, irreversible state (Holling et al. 1995). As a result, one of the most significant implications of the small rise in global temperature predicted to accompany climate change may be the effect on disturbance regimes (Sprugel 1991). If the theory of alternative states is correct, gradual changes in temperature may have little effect until a threshold is reached, when a large shift occurs that may be difficult to reverse (Scheffer and Carpenter 2003).

The unpredictable results of restoration efforts relying on a succession-based approach to reestablish historical disturbance regimes has fuelled an interest in the use of alternative ecosystem state models as a conceptual basis for the restoration of degraded systems (Suding et al. 2004). Ecological restoration is the process of assisting the recovery of an ecosystem that has been degraded, damaged, or destroyed (Society for Ecological Restoration 2004). Research into the restoration of degraded systems indicates that the dynamics of degraded systems that have shifted to a new state can be very different to those of the historical disturbance regime. Based on this work, it has been suggested that models of alternative states, that incorporate positive feedbacks and alternative internally reinforced states, may provide a valuable means of identifying and addressing the factors constraining restoration efforts.

\section{Instability and resilience}

Informed by ideas of deterministic, autonomous systems in which stability exists near an equilibrium steady state, classical ecology defines stability qualitatively in terms of system return to equilibrium following a perturbation (Pimm 1984). In its classical conception, the equilibrium model inherently excludes the fact that ecological systems are open and subject to continuous environmental changes at various temporal scales, and have the ability to adapt to these changes by a number of means (e.g., population fluctuations, species replacement, evolutionary change) (Loreau et al. 2002). In contrast, non-equilibrium ecology emphasizes the open and dynamic nature of ecological systems in which environmental change is a normal feature (Pickett and White 1985, Botkin 1990, Holling 1992), and may be required for the maintenance of ecosystem function (Turner 1998). From a long-term perspective, repeated disturbances (such as fire) may help maintain biodiversity and increase the chance that a given ecological system will persist (Langston 1998).

Informed by non-equilibrium dynamics, resilience may be understood in terms of conditions far from equilibrium, where disturbance can flip a system into another stability domain (Holling et al. 1995). In other words, this "ecological resilience" assumes that an ecosystem can exist in alternative selforganized or "stable" states (Holling 1973, May 1977). Ecological resilience is thus the capacity of a system to undergo disturbance and maintain its functions and controls, and may be measured by the magnitude of disturbance the system can tolerate and still persist. According to this view, attention should shift to determining the constructive role of instability in maintaining diversity and persistence, as well as to management designs that maintain ecosystem function in the face of unexpected disturbances (Holling et al. 1995). This would involve preserving the already built-in capacity of ecosystems to adapt to environmental perturbations (Loreau et al. 2002).

\section{The human dimension of biodiversity}

One of the most important insights from current developments in ecology is that human disturbances are now among the most important factors shaping ecosystem change (Langston 1998). Whereas classical ecology locates humans outside ecological systems, it is increasingly recognized that humans are an integral component of most ecosystems (McDonnell and Pickett 1993). Thus, strategies for biodiversity conservation cannot afford to overlook the active role of humans as primary agents of flux in ecosystems (Vitousek et al. 1997). Disturbance is thought to influence species diversity, system renewal, and ecosystem structure and function (McIntyre and Hobbs 1999). As such, the role of humans must be considered as an integral component in ecological, evolutionary, and environmental processes (Robertson and Hull 2001).

Human-induced land-use change currently has the largest effect on biodiversity, and other human- 
induced changes (e.g., climate change) may have an even greater influence in the future (Sprugel 1991). For example, most of the world's temperate landscape is subject to modification and consumptive use by humans (Franklin 1993). If disturbance (including human-induced disturbance) can cause systems to move between multiple stable states, it is reasonable to assume that under nonequilibrium conditions, the whole notion of "the" (unique) natural vegetation in an area is flawed (Sprugel 1991). Therefore, research cannot be restricted to "pristine" areas, but must focus on the altered systems prevalent today (Hobbs 1992, Vandermeer et al. 2002). Indeed, it has been argued that "many (most) important ecological questions are actually emerging from our efforts to apply existing knowledge in a real world setting, rather than in academic isolation" (Franklin 1995, cited in Hobbs 1998: 462). Thus, the conservation of biological diversity requires a dialogue between research and management in the context of humanmodified landscapes.

\section{Spatial Dynamics: Openness, Scale, and Heterogeneity}

Another feature of the classic equilibrium paradigm is the emphasis on closure. Ecological systems are considered to be homogenous or self regulating and, therefore, functionally and structurally complete (Pickett et al. 1992). Each species has its ordered position, and any disturbance triggers an ordered process of successional stages leading back to the original, stable, homeostatic, climax state (Hobbs and Morton 1999).

Recent developments in non-equilibrium ecology, in contrast, hold that ecological systems are open, heterogeneous systems (Ostfeld et al. 1997). The type and effect of ecological structures, and the perception of the stability of ecological functions, is thus assumed to be affected by scale (Levin 1992). Context becomes supremely important: the development of ecological systems is contingent on the particular history and biophysical conditions of the local environment (Parker and Pickett 1998). Moreover, ecosystems are not only internally variable across space and time, but their interaction at the landscape level means that one ecosystem can affect another (Turner 1998). This more contextual and integrated understanding of ecological systems suggests that research should attend to all levels of ecological organization and to multiple spatio- temporal scales.

Issues of variability across space and time, combined with the fact that most critical natural resource problems tend to occur at large spatial and temporal scales, point to the need for greater attention to landscape ecology. A landscape ecology approach provides an explicitly scale-related understanding of ecosystem diversity and functioning (Stalmans et al. 2001). Landscape ecology examines the interaction between spatial pattern (structure) and ecological processes (function); that is, it examines the causes and consequences of spatial heterogeneity across a range of scales (Turner 1998).

There is increasing recognition that disturbance (both natural and human induced) is the driver of patch dynamics (Pickett and White 1985, White and Jentsch 2001). The landscape consists of a continually changing mosaic of patches in different stages of succession, or a "shifting mosaic steady state" (Bormann and Likens 1979). However, this dynamic only exists under certain conditions: when the size of individual disturbance events is small relative to the size of the landscape, and when disturbed areas usually recover before they are disturbed again (Turner 1998). Disturbance is thus a central organizing concept at the landscape scale: equilibria are scale dependent and embedded in nonequilibrial conditions (Hobbs and Morton 1999, White and Jentsch 2001).

The fragmentation of natural landscapes by human activities, such as agricultural development, urbanization, and forestry, is now recognized as one of the major threats to biodiversity worldwide (Saunders et al. 1991). Reserves can no longer be the primary strategy for biodiversity conservation; it is the "semi-natural matrix" of unreserved land that not only dominates most inhabited regions of the world, but may also contain the majority of biological diversity (Franklin 1993). Therefore, although most management activities are site specific (at the level of the individual patch), these activities must be planned and undertaken within the landscape context.

When the landscape is conceived of in terms of a matrix, patchiness is a rapidly developing conceptual tool. Patchiness is a form of spatial heterogeneity that calls attention to the spatial matrix of ecological processes, and emphasizes the flux of materials and organisms in nature, 
encompassing the dynamics of mosaics and their parts (Ostfeld et al. 1997). The fragmented nature of habitat has also meant the continued relevance of the equilibrium theory of island biogeography (MacArthur and Wilson 1967). Fragments or patches function as islands, which restrict the movement of species. However, as not all humanmodified landscapes are characterized by a matrix devoid of all habitat, the fragmentation model may be too simplistic for some landscapes (Wiens 1994). Landscapes rather may be "variegated," consisting of scattered areas of original habitats in various states of modification, so that mapping the boundaries of discernible patches becomes an arbitrary endeavor (McIntyre and Barrett 1992, McIntyre and Hobbs 1999). The importance of the junctions between different patches (ecotones) in mediating the physical, chemical, and biotic flows between patches has, therefore, been discussed (Wiens et al. 1985).

The role of humans in increasingly fragmented habitats provides a strong practical reason for the adoption of patchiness as a guiding principle for conservation (Levin 1992, Ostfeld et al. 1997). Moreover, as there is no single correct scale at which ecological phenomena should be studied, patchiness is a concept that provides a common ground for population biologists and ecosystem ecologists (Levin 1992). Ecosystem processes and local disturbances critical to the maintenance of most species will exhibit variability and patchiness at a range of spatial and temporal scales.

\section{A PARADIGM SHIFT IN ECOLOGY?}

The idea of an inherent balance in nature has provided a strong argument for the conservation of biodiversity. When ecosystems are deterministic, the conservation of nature is a relatively straightforward task: leave ecological systems undisturbed and they will remain in balance, and retain their species composition and function, indefinitely. These assumptions have informed a number of conservation policies, including protected area and park management plans (Lister and Kay 1999).

Recent emphasis on non-equilibrium dynamics in theoretical ecology has prompted a number of responses from ecologists. One view is that the balance-of-nature paradigm is simply "wrong" (Botkin 1990). Another, however, admits the persistence of core ecological concepts from older ideas (e.g., concepts such as succession and equilibrium) in what has been dubbed the "new paradigm." Moreover, despite this emphasis on what is new in non-equilibrium ecology, it is often admitted that ecosystem change has a long history as a theme in ecology (Pickett and White 1985). As such, the new paradigm modifies rather than dismisses many of the older ideas.

The new paradigm in ecology can accept equilibrium or a point stable state as a special case, so it is inclusive rather than exclusive of important components of the older view. ... a landscape may be in compositional equilibrium even though individual patches may be in a variety of states, and individual patches change state through time. ... [The new paradigm] emphasizes process rather than end point. (Pickett et al. 1992: 70.)

It is this latter, transitional view of theoretical ecology that we believe provides a more accurate description of the state of affairs than more radical claims of a Kuhnian "paradigm shift" in ecology (Naeem 2002). Instructive is Alice Ingerson's (Ingerson 2002) observation that many paradigm shifts in ecology (as in other disciplines) look suspiciously like "Whig history"-history written by the victors. As such, the ways in which the "new" resembles the "old" may be conveniently forgotten.

The history of ideas in ecology reveals that the discipline has always been characterized by apparently antithetical concepts: coherence and creativity; interdependence and independence; holism and differentiation; continuity and change (Ingerson 2002). For example, Frederik Clements' notion of an orderly "succession" of communities culminating in a stable "climax" system has meant that he is often considered to be the father of equilibrium ecology (Ingerson 2002). Yet many historians of ecology have noted that Clements focused less on the way each organism helped to maintain a stable overall community than on the processes by which relative stability could, and only sometimes did, emerge from relative instability in nature. Persisting with the notion of a "paradigm shift" may, therefore, be counterproductive to advancing the discipline.

That said, ideas of non-equilibrium dynamics do suggest a number of important modifications to traditional concepts in ecology, which persist as guiding principles for management and policy 
despite their less-than-paradigmatic status.

\section{IMPLICATIONS FOR BIODIVERSITY CONSERVATION}

Developments in ecological concepts and theories over the past few decades, as summarized above, indicate a radical shift in the way ecosystems and their components are viewed. Very little of this shift was reflected in ecology textbooks until recently, and hence many conservation managers practicing today were trained in the "old school" of thought where things were more deterministic and predictable, stability was the norm, and disturbance was bad. The results of this can be seen in many parts of the world where conservation policy and management have been, or still are, largely about categorizing conservation values in terms of static species assemblages, purchasing and protecting conservation areas, isolating these from surrounding altered landscapes, and preventing human disturbance. Current controversial issues such as the wildfires in the western United States, which resulted from fire suppression policies or lack of fire management, are a direct result of this legacy (Fulé et al. 1997, Pollet and Omi 2002, Moore et al. 2004). Similarly, the immediate public reaction to the large wildfires in Yellowstone National Park in 1988 as being destructive and disastrous was largely dispelled by the rapid recovery of the forest ecosystem (Christensen et al. 1989, Romme and Despain 1989, Stone 1998, Baskin 1999).

A number of key messages for biodiversity conservation arise from the new ways of thinking about the temporal and spatial dynamics of ecosystems, respectively, which can be summarized as follows:

1. Ecosystems are complex and dynamic, and change in composition and structure can be expected over time. This can include both gradual change, as succession proceeds, and more rapid change, as a result of disturbance, episodic events, or changed management. In general, the structure, composition, and dynamics of an ecosystem in any particular place are contingent on its history (in terms of past disturbance, species' arrivals, deletions, and management). The temporal dynamics of ecosystems have a number of implications for management, including:
- Conservation reserves cannot be expected to remain static, but are likely to change over time. Simply giving legal protection to a conservation area does not guarantee that the systems within it will remain as they are currently. Different successional stages or alternative states are likely, and management goals must clarify which states are "acceptable" or "valuable" from a range of perspectives. Similarly restoration projects should consider whether setting a system back to some historical condition is possible or desirable (e.g., Hobbs 2004).

- Consideration must be given to the prevailing disturbance regimes, and these need to be incorporated into management strategies (Burrows and Abbott 2003). Disturbance is an integral part of many ecosystems, rather than an unwanted intrusion. Maintenance of natural disturbance regimes is thus important, and yet these regimes may often be significantly altered due to fragmentation or changes in land use (Sprugel 1991). It is also unlikely that a uniform regime will prevail across an entire area or suite of reserves and, thus, an appropriate strategy is likely to aim for a plurality of approaches (such as a range of fire frequencies rather than a uniform fire prescription) - i.e., not putting all one's eggs in one basket.

- Land use and disturbance legacies may be important elements in determining the current composition and structure of an ecosystem in any given place (Foster et al. 1998, Landres et al. 1999, Swetnam et al. 1999, Foster et al. 2003). Hence the link between the biotic assemblage and the abiotic setting may not always be straightforward. Thus, we may not be able to understand the distributions of species and ecosystems solely on the basis of local climate, geomorphology, and soil. This has important implications for setting conservation or restoration goals. Furthermore, it means that it will likely be difficult to predict impacts of climate change, except at very coarse levels. 
- By understanding the history of a place of interest, we may be better able to understand and predict future responses to management (Foster et al. 2003). As such, improved predictability may be possible and conservation goals can be sought using known disturbances to seek desired outcomes (Landres et al. 1999).

- Because rates of change can be highly variable, it is essential that managers maintain a "watching brief" over the systems they are managing. Managers may need to respond in very different ways to slow changes (such as climate change) and more rapid changes (such as those brought on by insect attack or fire). It is also important to recognize the potential interactions between slow and fast change. Integral to any understanding and management of change is monitoring (Noss 1990). Calls for monitoring have characterized biodiversity conservation for over two decades (Karr 1987); however, the urgency of such a need is emphasized as the basis of working with, if not managing, change. Suggestions for an integrated approach that incorporates inventory and monitoring, research, and adaptive management (e.g., Halvorson 2004) are pertinent here.

2. Ecosystems are open, heterogeneous systems that are not only internally variable across space and time, but also interact with other ecosystems at the landscape level. The structure, composition and dynamics of an ecosystem in any particular place are thus contingent on its spatial context (in terms of its position in relation to other systems, the extent to which surrounding systems interact, and the degree of human modification of the landscape). The implications of these spatial dynamics for management include:

- Because ecosystems are complex and are made up of many different species that interact in different ways, a management action with a simple aim and targeting a single ecosystem component is likely to have unexpected results that can cascade through the rest of the system. Hence, single-species management must be conducted in the broader context of the rest of the system, and single-issue management (e.g., fire management, or invasive species management) must similarly be considered as part of a broader systems approach (e.g., Zavaleta et al. 2001).

- The importance of landscape context in determining the internal dynamics of local systems means that small conservation reserves cannot simply be left to their own devices or be managed in isolation. Landscape-scale dynamics have the potential to completely overwhelm the internal dynamics of the system (e.g., Cramer and Hobbs 2002). Ideas such as conservation networks and buffer zones recognize this (e. g., Hobbs 2002). Moreover, increasing attention is being paid to the application of these ideas in the design of reserve networks at regional and continental scales (Soulé and Terborgh 1999). The landscape context is explicitly accounted for in the design of biosphere reserves, which incorporate core, buffer, and transition zones as a means to reconcile the conservation of biodiversity with its sustainable use (Dasmann 1988, Watson et al. 1995, Fall 1999, Heijnis et al. 1999).

- The landscape context has always been implicit in the design of nature reserves for biodiversity conservation, which recognized the need to provide links between reserves across fragmented natural landscapes. However, it has rarely been considered in reserve selection procedures, which mostly consider the representativeness and complementarity of individual remnants (Hobbs 1994).

- For rare species management, current ecological thinking emphasizes the importance 
of species planning and management that recognizes history and spatial context. History has been well addressed in management to date; however, the spatial context has been less well served. Recent shifts toward landscape-level recovery plans, and especially individual species plans embedded in landscape plans, suggest an increasing recognition of the importance of spatial positioning (Boyer 2001).

The changing views of how ecological systems work make the world a more complex and potentially confusing place for those managing biodiversity. Based on the theory of predictable succession in ecosystems, which assumes that nature will tend to take care of itself, management is essentially a passive endeavor. And because disturbance, based on this view, is an external and infrequent event, the preservation of natural communities has historically consisted of measures to protect them from physical disturbance. In contrast, the recognition that many forms of disturbance are important components of natural systems means that conservation efforts to preserve the biodiversity and functioning of natural systems must include explicit consideration of disturbance processes (Hobbs and Huenneke 1992). This requires active management: "Conservation efforts that attempt to wall off nature and safeguard it from humans will ultimately fail" (Meffe and Carroll 1994: 9).

Of great importance is scientific knowledge of alternative system states when active human intervention is required. Whereas the idea of predictable succession meant that ecological knowledge was not essential, management of environmental change requires knowledge of ecological processes and species' functional response to change. In turn, a primary management consideration must be the suite of adaptations and life histories of native species, ecological processes, and species' functional response to change (Hobbs and Huenneke 1992).

Crucial also for today's biodiversity conservation is clear goal setting. As ecosystems are unlikely to move predictably to some known endpoint, society (however defined) must collectively and collaboratively determine the desired goals (e.g., Robertson and Hull 2001). Those working in restoration ecology have begun to grapple with this approach (Box 1996,
Cairns 2000, Hobbs and Harris 2001, Hobbs 2004). Although ecologists must continue to provide scientific information, coupled with professional judgment on the feasibility and consequences of achieving alternative management goals, the choice of restoration and management goals should ultimately be a societal one (Lackey 2004). An active role for ecologists also exists in this new domain, one of recognizing that ecology must include societal values and other forms of knowledge, such as those held by indigenous and local peoples (Berkes et al. 2000, Robertson and Hull 2001).

An associated critical issue for both ecologists and managers is determining ways and means of including societal values in decisions about biodiversity management (Franz 2001, Ludwig et al. 2001, Davis and Slobodkin 2004). Practical suggestions to this end have been elaborated by Brown (2003), who focuses on three challenges for a "real people-centred conservation." First is the need for a more pluralist understanding of value systems, and of the ways different understandings, meanings, and values of biodiversity are integrated and applied to the setting and implementation of conservation goals. This requires a form of "fusion knowledge," created at the interface of different forms of knowledge and ways of knowing. Achieving this requires, second, the need for deliberative and inclusionary processes as a means of including the plural values, knowledges, and interests relevant to biodiversity conservation. The third challenge involves the creation of new flexible and adaptable institutions capable of evolving to accommodate the diverse values and knowledges recognized above, and of dealing with the complexity and uncertainty that characterize ecosystems, as highlighted by current ecological thinking.

Recognition of the need for an ecology that is directly engaged with society is increasingly widespread (e.g., Lubchenco 1998, Blockstein 1999, Bradshaw and Bekoff 2001, Robertson and Hull 2001). For one, Lubchenco (1998) urges the scientific community to re-examine its goals and to take responsibility for the contributions required to address the pressing environmental and social problems of contemporary society. The issue of scientific responsibility is also addressed by Kitcher (2004), who advocates for a democratic science that reflects on and takes responsibility for the ends (as well as the means) of scientific research, conducted 
by scientists who view themselves as agents for the public good.

The inclusion of humans in the ecosystem, and the uncertainties of non-linear system development, are two conceptual shifts associated with current ecological theory that challenge the capacity of scientists to be rigorous while, at the same time, fulfilling their social responsibilities. However, the rise of integrative approaches to the science-society relationship (Bradshaw and Bekoff 2001), together with discussions among scientists on this issue (Jasanoff et al. 1997), suggest that scientific rigor can be achieved in tandem with the production of knowledge to inform conservation policy and management decisions. Thus, the dynamism and unpredictability of natural systems do not mean that there are no criteria to guide the management of "natural" vegetation and ecosystem processes. Nor do they mean that defining the goals of ecological restoration, which will have an increasing role in biodiversity conservation and the repair of humaninduced damage and change (Young 2000), is an impossible task. Clearly, not all biotic assemblages (e.g., a large-scale, fertilized, pesticide-saturated crop) are "natural" by any reasonable definition (Sprugel 1991). Recognition that the legacies of land-use history shape the long-term structure, composition, and function of most ecosystems and landscapes, however, reinforces the conviction that the ultimate driver of management and policy goals is human values and perceptions (Foster et al. 2003).

\section{CONCLUDING REMARKS}

We have presented ecology as a science in transition, characterized by many significant shifts in emphasis and perspective, which in turn have important implications for biodiversity conservation. And yet many policies and plans for biodiversity conservation do not reflect these changing ideas. There remains a considerable gap between ecological knowledge and its integration into management and policy.

Conservation science has always adopted a leadership role in informing and affecting conservation policy (Robertson and Hull 2001). To maintain this role, ecologists need to ensure that new advances and theories are incorporated into strategies for policy and management (Brosnan 1995). If ecology is to maintain its status as "the relevant science," the information it generates must be reliable, and interpreted in a manner that provides useful insights to management and policy (Wiens 1997).

The review undertaken in this paper suggests that disturbance (both natural and human induced), historical contingency, multiple stable states, resilience, and the open, heterogeneous nature of ecological systems are concepts that dominate current ecological thinking. These concepts signify a broad shift in thinking about the spatial and temporal dynamics of ecosystems, which has significant implications for biodiversity conservation. In particular, it suggests that the structure, composition, and dynamics of an ecosystem in any particular place are contingent on its history and spatial context. Present ecosystem conditions must, therefore, be understood within the context of a trajectory of change, so that knowledge of the history and biophysical conditions of the local environment will be essential for management. Moreover, the scale-dependence of equilibrium conditions suggests that single-species and singleissue management strategies must consider system interactions at the landscape level, as well as the internal dynamics of the particular system in question.

Clearly, the empirical reality of many core concepts in non-equilibrium ecology is uncertain-a situation that leaves the conservation implications of the science open to divergent interpretations. Meanwhile, management decisions must still be made. Indeed, much ecological knowledge is being derived from damaged and managed ecosystems, so that the line between pure and applied ecology is fuzzier than it was once perceived to be. In the context of unparalleled human modification of ecological systems across the globe, these conditions provide a strong argument for building a more robust interface between research and management. This means that theory must inform application, and that successful application must test and inform theory (Lawton 1996).

Given the increased uncertainty about processes and outcomes that accompanies non-equilibrium ecology, there is an urgent need for ecologists to continue improving their efforts to communicate about probability and uncertainty with managers. With the possibility of multiple states and different responses to disturbance depending on contingency, it is essential that managers have the skills to deal with the associated uncertainties. Such uncertainties 
are further confounded by the unpredictabilities of ecosystem responses that seem to typify our current understanding. This more recent interest in uncertainty is in addition to longer held concerns regarding the limited understanding managers often have about related concepts such as Type I and II errors and the associated implications for biodiversity conservation (Schrader-Frechette and McCoy 1993).

As conservation biologists recognized from the beginning, conservation science cannot simply be a "science of discovery," but must also be a "science of engagement" (Meffe 2001). Fortifying the link between science and management is a constructive way to ensure that conservation science remains both rigorous and relevant. We hope that our paper stimulates discussion of that link and encourages more meaningful transfer of current ecological thinking into policy and management.

Responses to this article can be read online at: http://www.ecologyandsociety.org/vollo/iss 1/art15/responses/

\section{Acknowledgments:}

The research reported in this article was supported by a grant from the Australian Research Council "Designing and evaluating biodiversity conservation policies for the future" (Project ID: DP0344978). Useful comments on an earlier version of this paper by Lance Gunderson and two anonymous reviewers are gratefully acknowledged.

\section{LITERATURE CITED}

Barry, D., and M. Oelschlaeger. 1996. A science for survival: values and conservation biology. Conservation Biology 10(3):905-911.

Baskerville, G.L. 1997. Advocacy, science, policy, and life in the real world. Conservation Ecology 1 (1):9. [Online.] URL:

http://www.consecol.org/vol1/iss1/art9/.

Baskin, Y. 1999. Yellowstone fires: a decade later. BioScience 49(2):93-97.
Bellemare, J., G. Motzkin, and D. R. Foster. 2002. Legacies of the agricultural past in the forested present: an assessment of historical land-use effects on rich mesic forests. Journal of Biogeography 29:1401-1420.

Berkes, F., J. Colding, and C. Folke. 2000. Rediscovery of traditional ecological knowledge as adaptive management. Ecological Applications 10:1251-1262.

Blockstein, D. E. 1999. Integrated science for ecosystem management: an achievable imperative. Conservation Biology 13(3):682-685.

Bormann, F. H., and G. E. Likens. 1979. Pattern and process in a forested ecosystem. SpringerVerlag, New York, New York, USA.

Botkin, D. B. 1990. Discordant harmonies: a new ecology for the twenty-first century. Oxford University Press, Oxford.

Box, J. 1996. Setting objectives and defining outputs for ecological restoration and habitat creation. Restoration Ecology 4:427-432.

Boyer, D. M. 2001. Single-species versus multiplespecies recovery plans: a review of the Stock Island tree snail recovery plans. Endangered Species UPDATE 18(6):223-226.

Bradshaw, G. A., and M. Bekoff. 2001. Ecology and social responsibility: the re-embodiment of science. Trends in Ecology \& Evolution 16(8):460465.

Brosnan, D. M. 1995. Bridging gaps among ecology, law, and policy. Wildlife Society Bulletin 23(3):333-337.

Brown, K. 2003. Three challenges for a real peoplecentred conservation. Global Ecology and Biogeography 12:89-92.

Burrows, N., and I. Abbott. 2003. Fire in southwest Western Australia: synthesis of current knowledge, management implications and new research directions. Pages 437-452 in I. Abbott and N. D. Burrows, editors. Fire in ecosystems of southwest Western Australia. Backhuys, Leiden, the Netherlands.

Cairns, J. 2000. Setting ecological restoration goals 
for technical feasibility and scientific validity. Ecological Engineering 15:171-180.

Christensen, N. L., J. K. Agee, P. F. Brussard, J. Hughes, D. H. Knight, G. W. Minshall, J. M. Peek, S. J. Pyne, F. J. Swanson, J. W. Thomas, S. Wells, S. E. Williams, and H. A. Wright. 1989. Interpreting the Yellowstone fires of 1988. BioScience 39(10):678-685.

Cramer, V. A., and R. J. Hobbs. 2002. Ecological consequences of altered hydrological regimes in fragmented ecosystems in southern Australia: impacts and possible management responses. Austral Ecology 27:546-564.

Dasmann, R. F. 1988. Biosphere reserves, buffers and boundaries. BioScience 38:487-489.

Davis, M. A., and L. B. Slobodkin. 2004. Restoration ecology: the challenge of social values and expectations. Frontiers in Ecology 2:44-45.

Egerton, F. N. 1973. Changing concepts of balance of nature. Quarterly Review of Biology 48:322-350.

Fall, J. T. 1999. Transboundary biosphere reserves: a new framework for cooperation. Environmental Conservation 26(4):252-255.

Fiedler, P. L., P. S. White, and R. A. Leidy. 1997. The paradigm shift in ecology and its implications for conservation. Pages 83-92 in S. T. A. Pickett, R. S. Ostfeld, M. Shachak and G. E. Likens, editors. The ecological basis of conservation: heterogeneity, ecosystems, and biodiversity. Chapman and Hall, New York, New York, USA; London, UK.

Foster, D., F. Swanson, J. Aber, I. Burke, N. Brokaw, D. Tilman, and A. Knapp. 2003. The importance of land-use legacies to ecology and conservation. BioScience 53:77-88.

Foster, D. R., D. H. Knight, and J. F. Franklin. 1998. Landscape patterns and legacies resulting from large, infrequent forest disturbances. Ecosystems 1:497-510.

Franklin, J. F. 1993. Preserving biodiversity: species, ecosystems, or landscapes? Ecological Applications 3(2):202-205.

Franz, E. H. 2001. Ecology, values, and policy. BioScience 51(6):469-474.
Fulé, P. Z., W. W. Covington, and M. M. Moore. 1997. Determining reference conditions for ecosystem management of southwestern ponderosa pine forests. EcologicalApplications 7(3):895-908.

Gleason, H. A. 1926. The individualistic concept of the plant association. Torreya 53:7-26.

Gleason, H. A. 1927. Further views of the succession concept. Ecology 8:299-326.

Halvorson, W. 2004. Restoration ecology: the challenge of social values and expectations. Frontiers in Ecology 2:46-47.

Heijnis, C. E., A. T. Lombard, R. M. Cowling, and P. G. Desmet. 1999. Picking up the pieces: a biosphere reserve framework for a fragmented landscape-The coastal lowlands of the Western Cape, South Africa. Biodiversity and Conservation 8:471-496.

Hobbs, R. J. 1992. Is biodiversity important for ecosystem functioning? Implications for research and management. Pages 211-229 in R. J. Hobbs, editor. Biodiversity of Mediterranean ecosystems in Australia. Surrey Beatty \& Sons, Chipping Norton, NSW, Australia.

Hobbs, R. J. 1994. Landscape ecology and conservation: moving from description to application. Pacific Conservation Biology 1:170176.

Hobbs, R. J. 1998. Managing ecological systems and processes. Pages 459-484 in D. L. Peterson and V. T. Parker, editors. Ecological scale: theory and applications. Columbia University Press, New York and Chichester, New York, USA.

Hobbs, R. J. 2002. Habitat networks and biological conservation. Pages 150-170 in K. J. Gutzwiller, editor. Applying landscape ecology in biological conservation. Springer, New York, New York, USA.

Hobbs, R. J. 2004. Restoration ecology: the challenge of social values and expectations. Frontiers in Ecology 2:43-44.

Hobbs, R. J., and J. A. Harris. 2001. Restoration ecology: repairing the Earth's ecosystems in the new millenium. Restoration Ecology 9(2):239-246. 
Hobbs, R. J., and L. F. Huenneke. 1992. Disturbance, diversity, and invasion: implications for conservation. Conservation Biology 6(3):324337.

Hobbs, R. J., and S. R. Morton. 1999. Moving from descriptive to prescriptive ecology. Agroforestry Systems 45:43-55.

Holling, C. S. 1973. Resilience and stability of ecological systems. Annual Review of Ecology and Systematics 4:1-23.

Holling, C.S. 1986. Resilience of ecosystems: local surprise and global change. Pages 292-317 in W. C. Clark and R. E. Munn, editors. Sustainable development of the biosphere. Cambridge University Press, Cambridge, UK.

Holling, C. S. 1992. Cross-scale morphology, geometry, and dynamics of ecosystems. Ecological Monographs 62:447-502.

Holling, C. S. 1998. Two cultures of ecology. Conservation Ecology 2(2):4. [Online.] URL: http://www.consecol.org/vol2/iss2/art4/.

Holling, C. S., D. W. Schindler, B. W. Walker, and J. Roughgarden. 1995. Biodiversity in the functioning of ecosystems: an ecological primer and synthesis. Pages 44-83 in C. Perrings, K.-G. MGler, C. Folke, C. S. Holling and B.-O. Jansson, editors. Biodiversity loss: economic and ecological issues. Cambridge University Press, Cambridge, UK and New York, New York, USA.

Ingerson, A. 2002. A critical user's guide to "ecosystem" and related concepts in ecology. Institute for Cultural Landscape Studies, Harvard University, Cambridge, Massachussetts, USA. [Online.] URL:

http://www.icls.harvard.edu/ecology/ecology. html\#thescience.

Jasanoff, S., R. Colwell, M. S. Dressellhaus, G. W. T., R. D. Goldman, M. R. C. Greenwood, A. S. Huang, W. Lester, S. A. Levin, M. C. Linn, J. Lubchenco, R. S. Nicholson, M. J. Novacek, A. C. Roosevelt, J. E. Taylor, and N. Wexler. 1997. Conversations with the community: AAAS at the millennium. Science 278(5346):2066-2067.

Karr, J. R. 1987. Biological monitoring and environmental assessment: a conceptual framework. Environmental Management 11:249-256.

Kitcher, P. 2004. Responsible biology. BioScience 54(4):331-337.

Knight, R. L., and S. F. Bates, editors. 1995. A new century for natural resources management. Island Press, Washington, D.C., USA.

Lackey, R. T. 2004. Restoration ecology: the challenge of social values and expectations. Frontiers in Ecology 2:45-46.

Landres, P. B., P. Morgan, and F. J. Swanson. 1999. Overview of the use of natural variability concepts in managing ecological systems. Ecological Applications 9(4):1179.

Langston, N. E. 1998. People and nature: understanding the changing interactions between people and ecological systems. Pages $25-76$ in S. I. Dodson, T. F. H. Allen, S. R. Carpenter, A. R. Ives, R. L. Jeanne, J. F. Kitchell, N. E. Langston and M. G. Turner, editors. Ecology. Oxford University Press, New York, New York, USA and Oxford, UK.

Lawton, J. H. 1996. Corncrake pie and prediction in ecology. Oikos 76:3-4.

Levin, S. A. 1992. The problem of pattern and scale in ecology. Ecology 73(6):1943-1967.

Levin, S. A. 1999a. Fragile dominion: complexity and the commons. Perseus Publishing, Cambridge, Massachussetts, USA.

Levin, S.A. 1999b. Towards a science of ecological management. Conservation Ecology 3(2):6. [Online.] URL:

http://www.consecol.org/vol3/iss2/art6/.

Lister, N., and J. J. Kay. 1999. Celebrating diversity: adaptive planning and biodiversity conservation. Pages 189-218 in S. Bocking, editor. Biodiversity in Canada: an introduction to environmental studies. Broadview Press, Peterborough, Ontario, Canada.

Lister, N. E. 1998. A systems approach to biodiversity conservation planning. Environmental Monitoring and Assessment 49:123-155.

Loreau, M., A. Downing, M. Emmerson, A. 
Gonzalez, J. Hughes, P. Inchausti, J. Joshi, J. Norgerg, and O. Sala. 2002. A new look at the relationship between diversity and stability. Pages 79-91 in M. Loreau, S. Naeem and P. Inchausti, editors. Biodiversity and ecosystem functioning: synthesis and perspectives. Oxford University Press, Oxford, UK.

Lubchenco, J. 1998. Entering the century of the environment: a new social contract for science. Science 279:494-497.

Ludwig, D., M. Mangel, and B. Haddad. 2001. Ecology, conservation, and public policy. Annual Review of Ecology and Systematics 32:481-517.

MacArthur, R. H., and E. O. Wilson. 1967. The theory of island biogeography. Princeton University Press, Princeton, New Jersey, USA.

May, R. M. 1977. Thresholds and breakpoints in ecosystems with a multiplicity of stable states. Nature 269:471-477.

McDonnell, M. J., and S. T. A. Pickett, editors. 1993. Humans as components of ecosystems. The ecology of subtle human effects and populated areas. Springer Verlag, New York, New York, USA.

McIntyre, S., and G. W. Barrett. 1992. Habitat variegation, an alternative to fragmentation. Conservation Biology 6:146-147.

McIntyre, S., and R. J. Hobbs. 1999. A framework for conceptualising human effects on landscapes and its relevance to management and research models. Conservation Biology 13(6): 1282-1292.

Meffe, G. K. 2001. The context of conservation biology. Conservation Biology 15(4):815-816.

Meffe, G. K., and C. R. Carroll. 1994. Principles of conservation biology. Sinauer Associates, New York, New York, USA.

Moore, M. M., D. W. Huffman, P. Z. Fulé, W. W. Covington, and J. E. Crouse. 2004. Comparison of historical and contemporary forest structure and composition on permanent plots in southwestern ponderosa pine forests. Forest Science 50(2):162176.

Naeem, S. 2002. Ecosystem consequences of biodiversity loss. The evolution of a paradigm. Ecology 83:1537-1552.

Norton, B. G., and R. E. Ulanowicz. 1992. Scale and biodiversity policy: a hierarchical approach. Ambio 21(3):244-249.

Noss, R. 1990. Indicators for monitoring biodiversity: a hierarchical approach. Conservation Biology 44:355-364.

Ostfeld, R. S., S. T. A. Pickett, M. Shachak, and G. E. Likens. 1997. Defining the scientific issues. Pages 3-10 in S. T. A. Pickett, R. S. Ostfeld, M. Shachak and G. E. Likens, editors. The ecological basis of conservation: heterogeneity, ecosystems, and biodiversity. Chapman and Hall, New York, New York, USA and London, UK.

Pahl-Wostl, C. 1995. The dynamic nature of ecosystems: chaos and order entwined. Wiley, New York, New York, USA.

Parker, V. T., and S. T. A. Pickett. 1998. Historical contingency and multiple scales of dynamics within plant communities. Pages 171-192 in D. L. Peterson and V. T. Parker, editors. Ecological scale: theory and applications. Columbia University Press, New York and Chichester, New York, USA.

Peterson, G., C. R. Allen, and C.S. Holling. 1998. Ecological resilience, biodiversity, and scale. Ecosystems (1):6-18.

Pickett, S. T. A., J. Kolasa, and C. G. Jones. 1994. Ecological understanding: the nature of theory and the theory of nature. Academic Press, New York, New York, USA.

Pickett, S. T. A., V. T. Parker, and P. Fielder. 1992. The new paradigm in ecology: implications for conservation biology above the species level. Pages 65-88 in P. Fielder and S. Jain, editors. Conservation biology: the theory and practice of nature conservation. Chapman and Hall, New York, New York, USA.

Pickett, S. T. A., and P. S. White, editors. 1985. The ecology of natural disturbances and patch dynamics. Academic Press, New York, New York, USA.

Pimm, S. L. 1984. The complexity and stability of ecosystems. Nature 307:321-326. 
Pimm, S. L. 1991. The balance of nature? Ecological issues in the conservation of species and communities. University of Chicago Press, Chicago, Illinois, USA.

Pollet, J., and P. N. Omi. 2002. Effect of thinning and prescribed burning on crown fire severity in ponderosa pine forests. International Journal of Wildland Fire 11(1):1-10.

Robertson, D. P., and R. B. Hull. 2001. Beyond biology: toward a more public ecology for conservation. Conservation Biology 15(4):970979.

Romme, W. H., and D. G. Despain. 1989. The Yellowstone fires. Scientific American 261(5):3746.

Saunders, D. A., R. J. Hobbs, and C. R. Margules. 1991. Biological consequences of ecosystem fragmentation: a review. Conservation Biology 5:18-32.

Scheffer, M., and S. Carpenter. 2003. Catastrophic regime shifts in ecosystems: linking theory to observation. Trends in Ecology and Evolution 18 (12):648-656.

Schrader-Frechette, K. S., and E. D. McCoy. 1993. Method in ecology: strategies for conservation. Cambridge University Press, Cambridge, UK.

Scoones, I. 1999. New ecology and the social sciences: what prospects for a fruitful engagement? Annual Review of Anthropology 28:279-507.

Society for Ecological Restoration (SER) 2004. The SER primer on ecological restoration. Science \& Policy Working Group. [Online.] URL:

http://www.ser.org/pdf/primer3.pdf

Soulé, M. E., and J. Terborgh, editors. 1999. Continental conservation: scientific foundations of regional reserve networks. Island Press, Washington, D.C., USA.

Sprugel, D. G. 1991. Disturbance, equilibrium, and environmental variability: what is "natural" vegetation in a changing environment? Biological Conservation 58:1-18.
Stalmans, M., K. Balkwill, E. T. F. Witkowski, and K. H. Rogers. 2001. A landscape ecological approach to address scaling problems in conservation management and monitoring. Environmental Management 28(3):389-401.

Stone, R. 1998. Yellowstone rising again from ashes of devestating fires. Science 280:1527-1528.

Suding, K. N., K. L. Gross, and G. R. Houseman. 2004. Alternative states and positive feedbacks in restoration ecology. Trends in Ecology and Evolution 19:46-53.

Swetnam, T. W., C. D.Allen, and J. L. Betancourt. 1999. Applied historical ecology: using the past to manage for the future. Ecological Applications 9 (4):1189.

Turner, M. G. 1998. Landscape ecology: living in a mosaic. Pages 77-122 in S. I. Dodson, T. F. H. Allen, S. R. Carpenter, A. R. Ives, R. L. Jeanne, J. F. Kitchell, N. E. Langston and M. G. Turner, editors. Ecology. Oxford University Press, New York, New York, USA and Oxford, UK.

Vandermeer, J., D. Lawrence, A. Symstad, and S. Hobbie. 2002. Effect of biodiversity on ecosystem functioning in managed systems. Pages 221-233 in M. Loreau, S. Naeem and P. Inchausti, editors. Biodiversity and ecosystem functioning: synthesis and perspectives. Oxford University Press, Oxford, UK.

Vitousek, P. M., H.A. Mooney, J. Lubchenco, and J. Melillo. 1997. Human domination of Earth's ecosystems. Science 277:494-499.

Watson, J., W. Lullfitz, A. Sanders, and N. McQuoid. 1995. Networks and the Fitzgerald River National Park Biosphere Reserve, Western Australia. Pages 482-487 in D. A. Saunders, J. L. Craig and E. M. Mattiske, editors. Nature conservation 4: the role of networks. Surrey Beatty and Sons, Chipping Norton, New South Wales, Australia.

White, P., and A. Jentsch. 2001. The search for generality in studies of disturbance and ecosystem dynamics. Progress in Botany 62:399-450.

Wiens, J.A. 1994. Habitat fragmentation: island vs. landscape perspectives on bird conservation. Ibis 137:S97-S104. 
Wiens, J. A. 1997. Scientific responsibility and responsible ecology. Conservation Ecology $\mathbf{1}$ (1):16. [Online.] URL:

http://www.consecol.org/vol1/iss1/art16/.

Wiens, J. A., C. S. Crawford, and J. R. Gosz. 1985. Boundary dynamics: a conceptual framework for studying landscape ecosystems. Oikos 45:421-427.

Young, T. P. 2000. Restoration ecology and conservation biology. Biological Conservation 92:73-83.

Zavaleta, E. S., R. J. Hobbs, and H. A. Mooney. 2001. Viewing invasive species removal in a wholeecosystem context. Trends in Ecology \& Evolution 16(8):454-459. 